\title{
Radiation exposure in prone vs. modified supine position during PCNL: Results with an anthropomorphic model
}

\author{
Marie-Pier St-Laurent, MD'; Steve Doizi, MD²; Maéva Rosec, MD2; Jean-Baptiste Terrasa, MD; \\ Luca Villa, MD'; Olivier Traxer, MD2; Jonathan Cloutier, $M D^{1,2}$
}

'Laval University, Department of Urology, CHU de Québec, Quebec City, QC, Canada; ${ }^{2}$ Sorbonne Université, Hôpital Tenon, France

Cite as: Can Urol Assoc J 2019;13(8):246-9. hitp://dx.doi.org/10.5489/cuaj.6119

\section{Abstract}

Introduction: Radiation exposure during urological procedures is still of concern in the urology community. It has been reported that percutaneous nephrolithotomy (PCNL) in supine position has less irradiation, as the puncture is mostly done under ultrasound guidance. However, it can also be done under fluoroscopy guidance. Unfortunately, data on radiation exposure during PCNL is lacking since they are often drawn from generalization and extrapolation, or they do not evaluate new procedures or different positions. The aim of our study was to compare the radiation dose depending on the position of the surgeon during PCNL.

Methods: A portable C-arm was used in standard mode (32 impulsions/second; $98 \mathrm{kV}, 3.8 \mathrm{~mA}$ ). Specific dosimeters were placed for lens, extremity, and torso. Anthropomorphic models and hand phantom models were used to reproduce the position of surgeon and patient (with same bone density as human) during PCNL in prone and modified supine position. Fluoroscopy time (FT) was six minutes to obtain higher exploitable signal, and the results are given for a FT of three minutes (more realistic). Ten percent of the FT is done with an angulation of 15 degrees and the rest in anteroposterior position.

Results: The equivalent doses (ED) are given in uSV (uncertainty $k=2$ ). During the modified supine position: neck, lens, right index finger, left thumb, and index finger received EDs of $99(20 \%), 62$ $(18 \%), 437(10 \%), 112(12 \%)$, and $204(10 \%)$, respectively. In a prone position, the phantom received ED on the neck, lens, right thumb and index finger, left thumb and index finger of $85(20 \%), 92$ (12\%), $401(10 \%), 585(10 \%), 295(10 \%)$, and 567 (10\%), respectively. In both positions, the right hand seems more exposed than the left hand.

Conclusions: The effective dose is 1.5- and 1.3-fold higher for lens and extremities, respectively, in prone position PCNL compared to modified supine position. Both positions are still well below the recommended limit for professional exposure

\section{Introduction}

The use of radiation in urology has become common practice, especially since the introduction of endourological procedures in the 70s. In the operating room (OR), a portable $\mathrm{C}$-arm that generates ionizing radiation toward the patient is used to guide the surgeon during procedures. Scattered radiation from the patient is the major source of radiation to the personnel, and professional exposure is probably higher during percutaneous nephrolithotomy (PCNL) compared to other endourological procedures.

PCNL is the treatment of choice for stones larger than $2 \mathrm{~cm} \cdot{ }^{2,3}$ Alternative positions to the traditional prone position have been proposed to reduce some of the disadvantages PCNL, notably anesthetic and logistical ones. It is commonly reported that nephrolithotomy in the supine position has less irradiation, as the puncture is almost completely done under ultrasound guidance. ${ }^{4}$ However, the puncture on supine position can also be done under fluoroscopy guidance. Still, suggestions of reduced radiation to the surgeon's hands have been made, ${ }^{5}$ even without compelling data.

According to the International Atomic Energy Agency ${ }^{1}$ and Hellawell et $\mathrm{al}^{6}{ }^{6}$ in a typical uretheral fluoroscopy procedure, the surgeon receives about $12 \mu \mathrm{Gy}$ to the lower leg, about 6 $\mu \mathrm{Gy}$ to the foot, $2 \mu \mathrm{Gy}$ to the eyes, and $3 \mu \mathrm{Gy}$ to the hands (using $70 \mathrm{kV}$ and 2-3 mA). Unfortunately, data on PCNL are lacking, since they are often drawn from generalization and extrapolation, ${ }^{6}$ or on not evaluating new procedures or different positions. Safak et al reported mean radiation doses to eye, finger, and collar for the urologist during PCNL of 26, 33.5, and $48 \mu$ Gy per procedure, respectively, when using a lithium fluoride thermoluminescent dosimeter. ${ }^{7}$ Kumari et al reported the equivalent dose during a PCNL of 75 minutes on average, with a mean fluoroscopy screening time of 6.04 min (range 1.8-12.16). ${ }^{8}$ The mean radiation exposure dose to the patient was $0.56 \mathrm{mSv}$ (standard deviation $[\mathrm{SD}] \pm 0.35$ ), while the mean incident radiation exposure to the finger of the urologist was $0.28 \mathrm{mSv}(\mathrm{SD} \pm 0.13$ ). To our knowledge, no study has compared radiation exposition to the surgeon depending on PCNL position in the same control environment.

\section{Materials}

A portable C-arm (Siemens, Siremobil Compact L) was used in standard mode (32 impulsions/second; $98 \mathrm{kV}$ and 3.8 $\mathrm{mA}$ ). Before the experiment, a high-voltage control was performed to confirm the accurate display and to make sure there were no scattered emissions from the source. 
Anthropomorphic models were used to reproduce the position of surgeon and patient. The models offer the advantage of exposing the dosimeter to longer radiation than what the surgeon is usually exposed to. They also allow reproduction of geometrical exposures that were not commonly done during previous studies and give a steady environment for comparison purposes. Therefore, with the use of a passive dosimeter placed at the same spot on surgeons, we simulated longer exposure to radio-intervention to obtain higher exploitable signals and reduce the measurement uncertainty.

The torso model ATOM CIRS ${ }^{\circledR}$ type 701-706 was used (Fig. 1). It is composed of superimposed layers of $2.5 \mathrm{~cm}$ of epoxy resin over an internal skeletal, with the same bone density than an adult $\left(1.6 \mathrm{~g} / \mathrm{cm}^{3}\right)$, giving the phantom a composition similar to real human tissue. The anthropomorphic models used for hands had the same properties. Finger positions were made to represent those of a urologist performing the intervention. Distance between left index and thumb was $3 \mathrm{~cm}$, and $6 \mathrm{~cm}$ for the right hand.

Radiophotoluminescents (RPL) dosimeters were placed on the torso under the lead apron and over it on the neck. Thermoluminescent dosimeters (TLD) composed of lithium fluoride were used for measurement of lens (placed on forehead) and extremities (placed on distal phalange of thumb and index) exposure (similar to position on Fig. 2). The models were placed to reproduce surgeon and patient position during a prone (Fig. 3B) and modified supine (oblique decubitus) (Fig. 3A) PCNL. Fluoroscopy time (FT) was six minutes, but the results are given for a FT of three minutes (more realistic). Ten percent of the FT is done with an angulation of 15 degrees and the rest in anteroposterior position (Fig. 4).

The absorbed dose indicates the total radiation energy absorbed by a medium from an ionizing radiation and is measure in gray (Gy). The dose equivalent is derived from the absorbed dose and represents the stochastic health effects of ionizing radiation on the human body. It takes into account the biological effectiveness of the radiation, which is dependent on the radiation type and energy. The unit of the dose equiva-

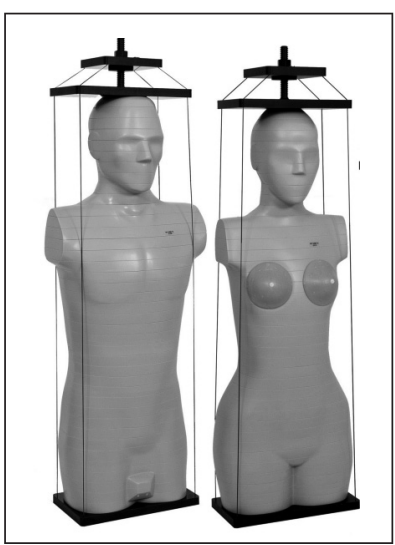

Fig. 1. Phantom ATOM CIRS ${ }^{\circledR}$ type 701-706 man and woman. lent is Sievert (Sv). Individual monitoring of external exposure is done with the personal dose equivalent, $H p(d)$, which was used in our study. Personal dose represents the dose equivalent in the tissue at a depth $d$ in a human body below the position where an individual dosimeter is worn, representative of the radiation exposure. The recommended depth dose ( $\mathrm{Hp})$ for whole body exposure with normal penetrating radiation is $\mathrm{d}=10 \mathrm{~mm}(\mathrm{Hp}=10)$ and for $\mathrm{a}$ weak penetrating radiation, a depth of $\mathrm{d}=0.07 \mathrm{~mm}$ is used to estimate skin dose $(\mathrm{Hp}=0.07){ }^{9}{ }^{9}$ For the dose to the lens of the eye, a depth $\mathrm{d}=3 \mathrm{~mm}$ has been proposed to be appropriate ${ }^{9,10}$ and was used.

The uncertainty $(K=2)$ of the equivalent dose $(E D)$ was calculated by applying the propagation of uncertainty formula (Fig. 5). Ninety-five percent confidence interval (Cl) was calculated and presented in the result section.

\section{Results}

Results are shown in Table 1. During modified supine position: neck, lens, right index finger, left thumb and index finger received EDs of 99 (20\%), 62 (18\%), 437 (10\%), 112 (12\%), and 204 uSv (10\%), respectively. In prone position, the phantom received EDs on the neck, lens, right thumb and index finger, left thumb and index finger of $85(20 \%)$, 92 (12\%), 401 (10\%), 585 (10\%), 295 (10\%), and 567 uSv $(10 \%)$, respectively.

In both positions, the right hand seems exposed more than the left hand. The index fingers are 1.5- (right hand) and 1.9-fold (left hand) more exposed than the thumbs. The dosimeter exposure seems to be higher in prone PCNL compare to the geometry exposure of modified supine PCNL by a factor 1.5 for lens ( $\mathrm{Hp}[3])$ and 1.3 for the hands $(\mathrm{Hp}[0.07])$ (comparison made from right index, which is the most exposed).

\section{Discussion}

Our study shows the radiation exposure that a urologist can expect to receive during a PCNL, in either prone or modified supine (oblique decubitus) position, with the use of fluoroscopy for about three minutes and with a C-arm in a standard
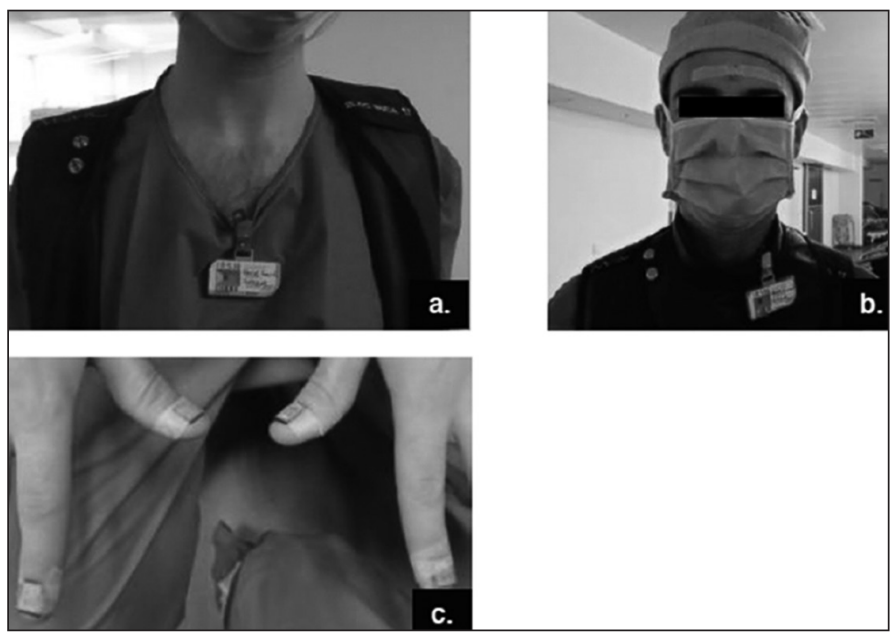

Fig. 2. Dosimeter position representation (a) Radiophotoluminescence (RPL) dosimeter on torso under lead apron; (b) RPL on neck and thermoluminescent dosimeters (TLD) for lens; (c) TLD on extremities. 


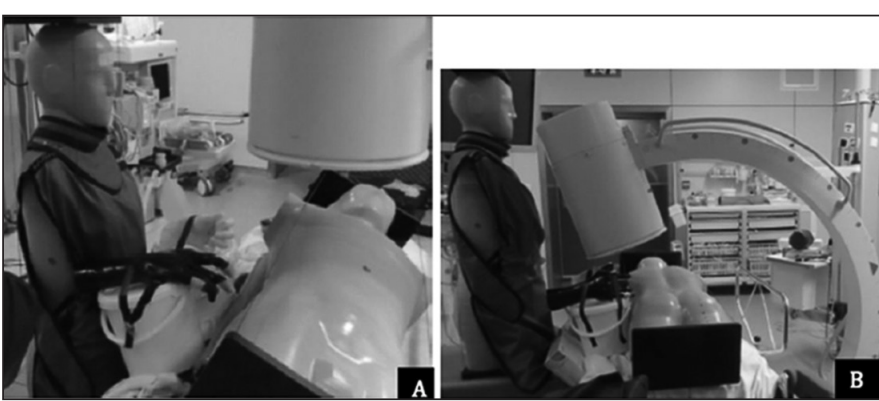

Fig. 3. Positioning of surgeon and patient during (A) modified supine percutaneous nephrolithotomy (PCNL); and (B) prone PCNL.

mode (32 impulsions/second; $98 \mathrm{kV}$ and $3.8 \mathrm{~mA}$ ). The methodology used allowed a prolonged exposure (six minutes) to enhance the signal and reduce the measurement uncertainty $(K=2)$. Even with this technique, the right thumb measurement in the modified supine position couldn't be exploited. Procedures requiring longer or shorter fluoroscopy periods than three minutes should take these results into consideration.

The results seem to show that the modified supine (oblique decubitus) position represents an advantage in terms of radioprotection, with a dosimeter gain of a factor 1.3 (extremities) and 1.5 (lens) when compared to prone position in our setting. In prone, the standing position of the surgeon brings his chest and extremities closer to the beam axis ( $5 \mathrm{~cm}$ and $10 \mathrm{~cm}$, respectively) compared with the modified supine. For this reason, the latter could be recommended to reduce the surgeon's dosimeter gain. However, conclusion on superiority of a technique can not be drawn from this study alone, since it has to be made with consideration of multiple factors (surgeon preferences and training, anesthesiology factors, time and logistics, stone-free rate, etc.), which was not the purpose of this study.

There are some limitations regarding the methodology of this study. The dosimeter uptakes were obtained using anthropomorphic models that recreate the bone density and human tissue composition, allowing reproduction of scatter radiation. However, no movement of hands, head or torso were made during the six-minute period. For this reason, our results can be overestimating the real exposition when the surgeon moves during the FT, turning his head to look at the screen or moving his hands while manipulating instruments. This could explain the higher dosimeter reading of lens and hands when compare to previous literature. Regardless, the lack of movement was equally present in both positions and, therefore, should have a similar effect on both sets of results when comparing the two.

Nevertheless, the use of anthropomorphic phantoms reduces the risks of wrongful compilation of data. Dosimeters worn by surgeons are at risk of systematic errors (not worn during operation, forgotten in OR, not worn in the right position, etc.), which were eliminated in our study design. A second study that includes surgeons wearing a dosimeter

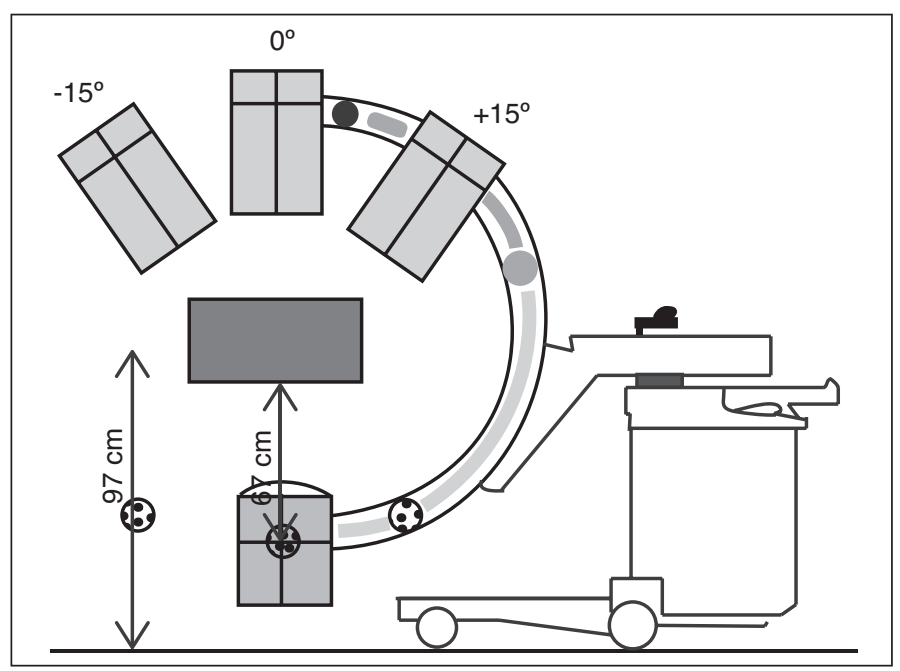

Fig. 4. Angulation and positioning of the $\mathrm{C}$-arm during percutaneous nephrolithotomy (prone and modified supine).

with good compliance would be interesting to compare or confirm our results.

No data from other body parts (legs) were evaluated, as we wanted to focus our work on organs at risks (lens, which are at risk for cataracts, ${ }^{11,12}$ and hands, which are closer to the source). However, Hellawell et $\mathrm{al}^{6}$ and Safak et $\mathrm{al}^{7}$ estimated a leg's ED at $167 \mu$ Sv and $137 \mu$ Sv per procedure position.

Our dosimeter results, even if possibly over-estimating surgeon exposure, are still well below the limit by organ set by the Canadian Radiation Protection Regulations (SOR/2000-203) (Table 2). ${ }^{13}$ However, those regulation do not yet take into account the new lens' dosimeter limit set by the International Commission on Radiological Protection (ICRP), which "now recommends an equivalent dose limit for the lens of the eye of $20 \mathrm{mSv}$ in a year, averaged over defined periods of five years, with no single year exceeding $50 \mathrm{mSv}$ " for an occupational exposure. ${ }^{14}$ With an average exposition of $20 \mu \mathrm{Sv}$ for lens per procedure, Hartmann et al showed that up to a mean of 1000 procedures per year could be performed by a surgeon (variety of surgery but no PCNL and surgeon experience taken into account) before reaching the new ICRP limit. ${ }^{15}$ With a higher ED result with our model in PCNL (62 and $92 \mu \mathrm{Sv}$ ), the position in modified supine PCNL seems to give an advantage to prevent cataract formation (ED reduction by a factor 1.5).

Any individual using ionized radiation in his field should be aware of its risks and observe radioprotection regulations.

$$
\begin{array}{lll}
X=\frac{Y}{Z} & \text { and } & \\
\frac{u(X)}{X}=\frac{Y(Y-Z}{\left(\frac{U}{Y}\right)^{2}+\left(\frac{u(Z)}{Z}\right)^{2}} & & \\
& &
\end{array}
$$

Fig. 5. The uncertainty $u(X)$ of the equivalent dose (ED) calculated by applying the propagation of uncertainty formula. 


\begin{tabular}{|c|c|c|}
\hline \multirow{2}{*}{$\begin{array}{l}\text { Dosimeter position } \\
\text { Equivalent dose ( } \mu \mathrm{Sv}) \\
\text { (Uncertainty } \mathrm{K}=2 \text { ) }\end{array}$} & \multicolumn{2}{|c|}{ Intervention } \\
\hline & $\begin{array}{c}\text { Modified supine (oblique } \\
\text { decubitus) PCNL } \\
\text { ED in } \mu \text { Sv (Cl) }\end{array}$ & $\begin{array}{l}\text { Prone PCNL } \\
\text { ED in } \mu \mathrm{Sv}(\mathrm{Cl})\end{array}$ \\
\hline Chest $[\mathrm{Hp}(10)]$ & $<$ LOD & $<\mathrm{LOD}$ \\
\hline Neck [Hp(10)] & $99(20 \%)$ & $85(20 \%)$ \\
\hline Lens [Hp(3)] & $62(18 \%)$ & $92(12 \%)$ \\
\hline Right thumb $[\mathrm{Hp}(0.07)]$ & NE & $401(10 \%)$ \\
\hline Left thumb [Hp(0.07)] & $112(12 \%)$ & $295(10 \%)$ \\
\hline Right index [Hp(0.07)] & $437(10 \%)$ & $585(10 \%)$ \\
\hline Left index $[\mathrm{Hp}(0.07)]$ & $204(10 \%)$ & $567(10 \%$ \\
\hline \multicolumn{3}{|c|}{$\begin{array}{l}\text { LOD: Limit of detection estimate at } 10 \mu \mathrm{Sv}: \mathrm{Hp}(10), 13 \mu \mathrm{Sv}: \mathrm{Hp}(3), 10 \mu \mathrm{Sv}: \mathrm{Hp}(0.07) \text {. Cl: } \\
\text { confidence interval; ED: equivalent dose; NE: Not exploitable; PCNL: percutaneous } \\
\text { nephrolithotomy. }\end{array}$} \\
\hline
\end{tabular}

For example, using a $0.5 \mathrm{~mm}$ lead apron reduces X-ray exposure by a factor 40, and leaded glasses by a factor 7 .

\section{Conclusions}

The effective radiation doses are 1.5- and 1.3-fold higher for lens and extremities, respectively, in a prone position PCNL compared to a modified supine position. Both positions are still well below the recommended limit for professional exposure. An average of 322 modified supine PCNL or 217 prone PCNL (with a total fluoroscopy time of three minutes) could be done within a year by a single surgeon before reaching the new ICRP recommendation for lens exposure.

Competing interests: The authors report no competing personal or financial interests related to this work.

Acknowledgments: Special thanks to Mario Chretien, physicist from CHU of Quebec-Laval University, for the review and comments.

This paper has been peer-reviewed.

\section{References}

1. International Atomic Energy Agency. Radiation protection of staff in urology. n.d. [cited 2018 september 23rd 2018]; Available at https://www.iaea.org/resources/rpop/health-professionals/other-specialitiesand-imaging-modalities/urology/staff. Accessed June 18, 2019.

2. Assimos D, Krambeck A, Miller NL, et al. Surgical management of stones: American Urological Association/ Endourological Society guideline, part I. J Urol 2016;196:1153-60. https://doi.org/10.1016/i. juro.2016.05.090

3. Wein AJ, et al. Campbell-WalshUurology. 11e ed. 2016, Philadelphia, Pennsylvania: Elsevier.

\begin{tabular}{|c|c|c|c|c|}
\hline & Column 1 & Column 2 & Column 3 & Column 4 \\
\hline Item & $\begin{array}{c}\text { Organ or } \\
\text { tissue }\end{array}$ & Person & Period & ED (mSV) \\
\hline \multirow[t]{2}{*}{1} & $\begin{array}{l}\text { Lens of an } \\
\text { eye }\end{array}$ & $\begin{array}{l}\text { (a) Nuclear } \\
\text { energy worker }\end{array}$ & $\begin{array}{c}\text { One-year } \\
\text { dosimetry period }\end{array}$ & 150 \\
\hline & & $\begin{array}{l}\text { (b) Any other } \\
\text { person }\end{array}$ & One calendar year & 15 \\
\hline \multirow[t]{2}{*}{2} & Skin & $\begin{array}{l}\text { (a) Nuclear } \\
\text { energy worker }\end{array}$ & $\begin{array}{c}\text { One-year } \\
\text { dosimetry period }\end{array}$ & 500 \\
\hline & & $\begin{array}{l}\text { (a) Any other } \\
\text { person }\end{array}$ & One calendar year & 50 \\
\hline \multirow[t]{2}{*}{3} & $\begin{array}{l}\text { Hands and } \\
\text { feet }\end{array}$ & $\begin{array}{l}\text { (a) Nuclear } \\
\text { energy worker }\end{array}$ & $\begin{array}{c}\text { One-year } \\
\text { dosimetry period }\end{array}$ & 500 \\
\hline & & $\begin{array}{l}\text { (b) Any other } \\
\text { person }\end{array}$ & One calendar year & 50 \\
\hline
\end{tabular}

From the Radiation Protection Regulations SOR/2000-203. ${ }^{13}$ Available at: http://laws-lois. justice.gc.ca/eng/regulations/SOR-2000-203/FullText.html. ED: equivalent dose.

4. Breda A, Territo A, Scoffone $C$, et al. The evaluation of radiologic methods for access guidance in percutaneous nephrolithotomy: A systematic review of the literature. Scand J Urol 2018;52: 81-6. https://doi.org/10.1080/21681805.2017.1394910

5. Duty B, Okhunov Z, Smith A, et al. The debate over percutaneous nephrolithotomy positioning: A comprehensive review. J Urol 2011;186:20-5. https://doi.org/10.1016/i.juro.2011.02.2693

6. Hellawell $\mathrm{GO}$, Mutch SJ, Thevendran $\mathrm{G}$, et al. Radiation exposure and the urologist: What are the risks? J Urol 2005; 174:948-52; discussion 952. htrps://doi.org/10.1097/01.ju.0000170232.58930.8f

7. Safak M, Olgar T, Bor D, et al. Radiation doses of patients and urologists during percutaneous nephrolithotomy. J Radiol Protect 2009;29:409. https://doi.org/10.1088/0952-4746/29/3/005

8. Kumari $G$, Kumar $P$, Wadhwa $P$, et al, Radiation exposure to the patient and operating room personnel during percutaneous nephrolithotomy. Int Urol Nephrol 2006;38:207. https://doi.org/10.1007/ s1 1255-005-4972-9

9. ICRP, The 2007 recommendations of the International Commission on Radiological Protection. ICRP publication 103; vol. 2007.

10. Bolch WE, Dietze G, Petoussi-Henss N, et al. Dosimetric models of the eye and lens of the eye and their use in assessing dose coefficients for ocular exposures. Ann ICRP 2015; 44:91-111. https://doi.org/10.1177/0146645314562320

11. Stewart FA, Akleyev AV, et al. ICRP publication 118: ICRP statement on tissue reactions and early and late effects of radiation in normal tissues and organs — threshold doses for tissue reactions in a radiation protection context. Ann ICRP 2012;4:1-322. https://doi.org/10.1016/ji.icrp.2012.02.001

12. Rao SB. Biological bases for the revision of dose limits to the eye lens. J Med Physics 2016;41:211-3. https://doi.org/10.4103/0971-6203.195183

13. Governor General in Council, Radiation Protection Regulations, in (SOR/2000-203), Minister of Natural Resources, Editor. 2000: Official Gazette, Statutory Instruments, 2000-06-21;134:1171-83.

14. International Commission on Radiological Protection, Statement on Tissue Reactions. 2011: ICRP ref 4825-3093-1464. Approved by the Commission on April 21, 2011.

15. Hartmann J, Distler F, Baumüller M, et al. Risk of radiation-induced cataracts: Investigation of radiation exposure to the eye lens during endourologic procedures. J Endourol 2018;32:897-903. https://doi.org/10.1089/end.2018.0324

Correspondence: Dr. Marie-Pier St-Laurent, Laval University, Department of Urology, CHU de Québec, Quebec City, QC, Canada; marie-pier.st-laurent.3@ulaval.ca 